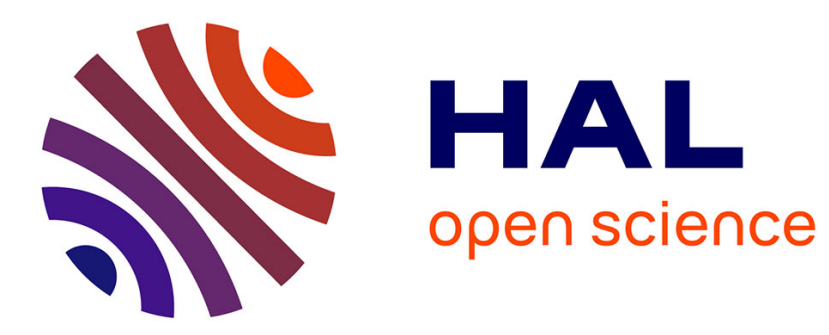

\title{
The morphosyntax-semantics interface and the Sicilian Doubly Inflected Construction *
}

\author{
Giuseppina Todaro, Fabio Del Prete
}

\section{To cite this version:}

Giuseppina Todaro, Fabio Del Prete. The morphosyntax-semantics interface and the Sicilian Doubly Inflected Construction *. Italian Dialectology at the Interfaces, Italian Dialectology at the Interfaces, John Benjamins Publishing Company, pp.131-154, 2019, Linguistik Aktuell/Linguistics Today, 9789027201768. hal-01810882

\section{HAL Id: hal-01810882 \\ https://hal.science/hal-01810882}

Submitted on 8 Jun 2018

HAL is a multi-disciplinary open access archive for the deposit and dissemination of scientific research documents, whether they are published or not. The documents may come from teaching and research institutions in France or abroad, or from public or private research centers.
L'archive ouverte pluridisciplinaire HAL, est destinée au dépôt et à la diffusion de documents scientifiques de niveau recherche, publiés ou non, émanant des établissements d'enseignement et de recherche français ou étrangers, des laboratoires publics ou privés. 


\title{
The morphosyntax-semantics interface and the Sicilian Doubly Inflected Construction ${ }^{*}$ Giuseppina Todaro, Fabio Del Prete \\ CLLE-ERSS (CNRS \& Université de Toulouse II)
}

\begin{abstract}
We examine the Doubly Inflected Construction of Sicilian (DIC, Cruschina 2013; also known as Inflected Construction, Cardinaletti and Giusti 2001, 2003), in which a motion verb $\mathrm{V}_{1}$ is followed by an event verb $\mathrm{V}_{2}$, both verbs being inflected for the same person and TAM features. We propose to regard DIC as a Serial Verb Construction and analyze it in terms of an operation of lexical concatenation, whereby $\mathrm{V}_{1}$ and $\mathrm{V}_{2}$ are semantically composed as lexical verbs denoting spatio-temporally contiguous events and displaying argument sharing, to yield a complex predicate denoting concatenated events. The data we consider crucially include the causative motion verb 'send' and bring out a mismatch between the person features realized on $V_{1}$ and $V_{2}$ and semantic interpretation. We show how our analysis allows for a principled account of the morphology-semantics mismatch. The semantic analysis is implemented in a neoDavidsonian framework (Parsons 1990).
\end{abstract}

Keywords Doubly Inflected Construction; Serial verb constructions; Motion verbs; Morphosyntax-semantics mismatch; Event semantics

\section{Introduction}

This paper focuses on the Doubly Inflected Construction (hereafter, DIC), a morphosyntactic construction attested in Sicilian and illustrated by $(1):^{1}$

$\begin{array}{lllll}\text { Vaju } & \text { a } & \text { mmanciu } & \text { a } & \text { casa. } \\ \begin{array}{l}\text { go-1sG.PRS.IND } \\ \text { 'I go eat at home.' }\end{array} & a^{2} & \text { eat-1SG.PRS.IND } & \text { to } & \text { home }\end{array}$

\footnotetext{
${ }^{*}$ Previous versions of this work were presented at CIDSM 2016 (University of Vienna), at the workshop The profile of event delimitation (SLE 2016 conference, University of Naples) and at the Institut Jean-Nicod LANGUAGE Seminar. We greatly benefited from invaluable feedback from the participants to these events. Special thanks go to Patrícia Amaral, Michel Aurnague, Lucas Champollion, Vincenzo Di Caro, Giuliana Giusti, Tatiana Nikitina, Jesse Tseng and Sandro Zucchi for discussion of specific aspects of this paper.

${ }^{1}$ We use the expression 'Doubly Inflected Construction' following Cruschina (2013), but the same phenomenon has been described in the literature under different headings, such as Costruzione paratattica (Sornicola 1986), Inflected Construction (Cardinaletti and Giusti 2001, 2003; Di Caro 2015; Di Caro and Giusti 2015) and, in ongoing researches, pseudo-coordination (Di Caro 2017, this volume; Wiklund 1996, 2007 uses this term to refer to similar syntactic structures in Swedish).

${ }^{2}$ We avoid glossing the connecting element $a$ of DIC so as not to prejudge its categorial status. For more details on the latter, see section 3.1.1.
} 
DIC is found in all varieties of Sicilian, with micro-variations among them (see Di Caro's contribution in this volume and section 2 of this paper for more details). The data we present in this paper all belong to the variety of Trapani, unless otherwise specified. In DIC, a motion verb $\mathrm{V}_{1}$, from a class which exhaustively includes iri 'go', vèniri 'come', passari 'pass', and mannari 'send', is followed by an event verb $\mathrm{V}_{2}$, with the two verbs being inflected for the same person and TAM features (Feature Matching). DIC must be distinguished, both morphosyntactically and semantically, from a neighboring construction which is far more common in Romance languages, that is, the infinitival construction, exemplified in (2), in which $\mathrm{V}_{1}$ is inflected and $\mathrm{V}_{2}$ is in the infinitive form:

$$
\begin{array}{lll}
\text { Vaju } & \text { a mmanciari a casa. } \\
\text { go-1SG.PRS.IND to eat-INF } & \text { to home } \\
\text { 'I go to eat at home.' } & &
\end{array}
$$

The plan of this paper is the following. In section 2 we review syntactic and semantic evidence from the previous literature showing that DIC is a monoclausal construction in which $\mathrm{V}_{1}$ and $\mathrm{V}_{2}$ form a complex predicate referring to a single event; we also contribute new data supporting the view of a full lexical content for both $\mathrm{V}_{1}$ and $\mathrm{V}_{2}$ in DIC. In section 3 we argue that DIC is an asymmetrical Serial Verb Construction (Aikhenvald 2006, 2011) by showing that it is characterized by typical "serial verb" properties. In section 4, first we consider data with the causative motion verb mannari which give rise to a morphosyntax-semantics mismatch; the data are difficult to account for on previous syntactic analyses which are based on the idea that $V_{1}$ is auxiliary-like and $\mathrm{V}_{2}$ is the lexical head of DIC. Then we present an analysis of DIC with two main properties: on the one hand, it accounts for the morphosyntactic properties of the complex (serial) predicate, including the particular way in which inflectional features are realized on $\mathrm{V}_{1}$ and $\mathrm{V}_{2}$, on the basis of an operation of lexical concatenation which takes the component verbs $\mathrm{V}_{1}$ and $\mathrm{V}_{2}$ as inputs and yields a "concatenated predicate" [ $\mathrm{V}_{1}$ a $\left.\mathrm{V}_{2}\right]$ as output; on the other hand, it accounts for the semantics of DIC by positing that $V_{1}$ and $V_{2}$ enter the semantic composition as lexical verbs each contributing an event to the sentence meaning, with the two events undergoing an operation of Event Concatenation. Section 5 concludes by raising some questions about the productivity of DIC and the applicability of our analysis to other cases of serialization.

\section{Main properties of DIC}

In this section, we consider morphosyntactic and semantic properties of DIC that distinguish it from well-known constructions in other Romance languages. In particular, the doubly realized inflection and the syntactic properties supporting its monoclausal status (section 2.1), alongside the semantic properties bearing on the sort of event structure it involves (section 2.2), distinguish DIC from the well-known infinitival construction with motion verbs, which underwent grammaticalization in languages like French (section 2.3). 


\subsection{Morphosyntactic properties}

Based on recent fieldwork conducted by the author, Di Caro (2017, this volume) reports a great variability in the morphosyntactic realization of DIC across different varieties of Sicilian and he proposes a typology of DIC based on the following criteria: (c1) whether and how the paradigm is defective, (c2) what particular motion verbs are allowed as $\mathrm{V}_{1}$ - whether all four verbs mentioned at the outset (iri, vèniri, passari, and mannari) or only some of them -, (c3) what sorts of verbs are allowed as $V_{2}$, and whether there is an interaction between the type of verb in $V_{2}$ and the aspects mentioned in (c1)-(c2). In light of the criteria in (c1)-(c3), he proposes a classification of DIC in three Types: Type 1, represented by the western Sicilian variety of Marsalese, is characterized by a restricted availability of the construction in the indicative present (limited to $1 \mathrm{sg}, 2 \mathrm{sg}, 3 \mathrm{sg}$ and $3 \mathrm{pl}$ ) and in the imperative mood (limited to 2sg); Type 2, represented by the central Sicilian variety of Deliano, is characterized by a larger availability of the construction, which can also occur in the indicative imperfect, preterite and in the subjunctive mood; finally, Type 3, represented by eastern Sicilian varieties, is characterized by a full-fledged paradigm in the indicative present, imperfect, preterite, and in the subjunctive and the imperative, but it is limited to an invariable reduced form of $\mathrm{V}_{1}=g o$. The DIC from Trapani's variety falls under Type 1 of this typology: (a) it is only available in the present tense; (b) it has the defective paradigm 1sg, 2sg, 3sg and 3pl (identified by Cruschina 2013 with Maiden's 2004 N-pattern); (c) the position of $\mathrm{V}_{1}$ includes a closed class of verbs including iri 'go', vèniri 'come', passari 'pass', and mannari 'send', while $\mathrm{V}_{2}$ corresponds to an event verb.

\subsubsection{Feature Matching}

DIC exhibits Feature Matching: the person and TAM features on $\mathrm{V}_{1}$ and $\mathrm{V}_{2}$ must be the same (Cardinaletti and Giusti 2001, 2003). This is shown, for person features, by the contrast in (3a,b):

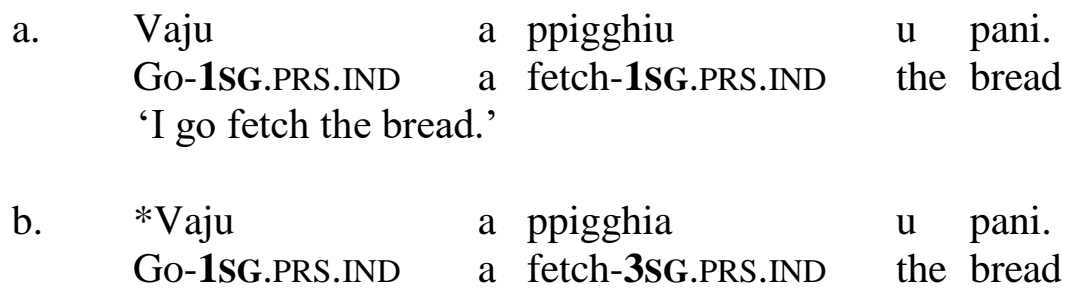

Sentence (3a), in which $\mathrm{V}_{1}$ and $\mathrm{V}_{2}$ have the same person/TAM features (Feature Matching), is a good DIC and gets the reading indicated by the gloss; the minimally different sentence (3b), however, in which $V_{2}$ crucially differs from $V_{1}$ with respect to the person feature, is ungrammatical - in particular, (3b) cannot mean that I am going to some contextually relevant place and a third person is fetching the bread.

As we have noted above, the varieties falling under Di Caro's Type 2 present an extension of the available slots of the paradigm to some persons of the indicative imperfect and preterite. If we look at Type 2 varieties, we observe that Feature Matching also extends to tense and aspect features. Thus, structures with mixed tense/aspect properties, as shown in (4b) and (5b), are not 
acceptable instances of DIC: ${ }^{3}$

a. Vegnu

a ppigghiu

u pani.

come-1SG.PRS.IND

a fetch-1SG.PRS.IND

the bread

'I come fetch the bread.'

b. *Vegnu come-1SG.PRS.IND

a ppigghiaiu

a fetch-1SG.PST.IND u pani.

the bread a. Ìa

Go-1SG.IMPF.IND a ppigghiava

a fetch-1SG.IMPF.IND u pani.

the bread 'I was going/would go fetch the bread.'

b. *İa

Go-1SG.IMPF.IND a ppigghiaiu

a fetch-1SG.PST.IND u pani.

the bread

Unlike their minimally different counterparts with matching features (4a) and (5a), which are both acceptable as DICs and obtain the readings indicated by the glosses, sentence (4b), involving a tense mismatch, and sentence (5b), which involves an aspect mismatch, are both ungrammatical - in particular, (4b) cannot mean that I am coming (to some place) now and I fetched the bread before, and (5b) cannot mean that I was going (to some place) and I fetched the bread on my way.

\subsubsection{No intervening elements}

As Cardinaletti and Giusti (2001: 389-390) shows, no linguistic element other than the connecting particle $a$ can be inserted between $\mathrm{V}_{1}$ and $\mathrm{V}_{2}$ in DIC. In particular, neither clitic pronouns (6a) nor quantifying elements (7a) can:
a. (Lu) vaju a (*lu) accattu
it-CL go-1SG a it-CL buy-1SG
'I'll go buy it.'
b. Vaju e lu accattu.
go-1SG and it-CL buy-1SG
'I'll go and I'll buy it.'

\footnotetext{
3 These examples come from the variety of Leonforte, in the province of Enna. This variety allows for both imperfective and perfective past in DIC (Basilio Calderone and Angela Prestifilippo, p.c.).
} 
a. I picciotti vannu (*sempri) a ppigghianu (sempri) u pani the boys go-3PL always a fetch-3PL always the bread ne sta putìa.

in this shop

'The boys always go buy bread in this shop.'

b. I picciotti vannu sempri a ppigghiari $u$ pani ne sta putìa. the boys go-3PL always to fetch-INF the bread in this shop 'The boys always go to buy bread in this shop.'

This is in sharp contrast with what we find in coordinations $\left[\mathrm{V}_{1}\right.$ and $\left.\mathrm{V}_{2}\right]$ and subordinations $\left[\mathrm{V}_{1}\right.$ to $\mathrm{V}_{2}$ ], as shown in (6b) and (7b) above.

\subsubsection{No syntactic dependency}

A property of DIC which distinguishes it from coordinate structures is based on wh-extraction facts relating to Ross' (1967) Coordinate Structure Constraint. ${ }^{4}$ Consider (8a,b) (C\&G 2003: 33):

a. $\quad \mathrm{Cu}$ soccu vai a aggiusti a machina?

With what go-2SG a fix-2sG the car

'What do you go and fix the car with?'

b. $\quad *$ Cu soccu vai e aggiusti a machina?

With what go-2SG and fix-2SG the car

In (8a), but not in (8b), we can extract the object of $\mathrm{V}_{2}$ through the interrogative pronoun soccu 'what'. If vai a mmanci in (8a) were a coordinate structure (as vai e manci in (8b)), extraction of the direct object of manci would result in an unacceptable sentence.

We note that DIC also displays what we may call "locality effects" which sharply distinguish it from subordinations. This is shown in $(9 \mathrm{a}, \mathrm{b})$, for the possibility of left dislocation of $\left[a \mathrm{~V}_{2}\right]$, and in $(10 \mathrm{a}, \mathrm{b})$, for the possibility of uttering $\left[\mathrm{a} \mathrm{V}_{2}\right]$ in isolation as an answer to a wherequestion:
a. $\quad *$ A mmanciu vaju.
a eat-1SG go-1SG
b. A mmanciari vaju.
a eat-INF go-1SG
'I'm going to eat.'

\footnotetext{
${ }^{4}$ See also Cardinaletti and Giusti (2003), Manzini and Savoia (2005: 700-701) and Cruschina (2013: 268) on this point.
} 

a. Q: Unni vai?
A: *A mmanciu.
where go-2SG
a eat-1SG
b. Q: Unni vai?
A: A mmanciari.
to eat-INF
'Q: Where are you going? A: To eat.'

The data in (3-10) compellingly show that $\mathrm{V}_{1}$ and $\mathrm{V}_{2}$ in DIC behave as a single predicate heading a single clause.

\subsection{Semantic properties}

Cardinaletti and Giusti (2001) try to show that the interpretation of a DIC involves a single event, in spite of the occurrence of two verb predicates (see also Cruschina 2013: 267). The authors use a test which is based on modification by the time adverb gnignornu 'every day' to show that there is a contrast between DIC and the infinitival construction with respect to what event is accessible for modification. They consider the contrast of acceptability between (11a) and (11b):
a. Vaju a accattari a cicoria gnignornu, ma unn' a trovu mai. go-1SG to buy-INF the chicory every-day but not it-CL find-1SG never 'I go to buy chicoree every day, but I never find it.'
b. ?Vaju a accatto a cicoria gnignornu, ma unn' a trovu mai. go-1SG a buy-1SG the chicory everyday but not it-CL find-1SG never 'I go and buy chicoree every day, but I never find it.'

While (11a) has the consistent reading 'On every day, I go to a contextually relevant place in order to buy chicoree there, but I never find chicoree there', (11b) has the inconsistent reading 'On every day, I go and buy chicoree, but I never find chicoree'. Cardinaletti and Giusti make the following remarks: (i) gnignornu only modifies the motion verb in (11a), thus this discourse entails that an event of going occurs on every day, while it does not entail that an event of buying chicoree occurs on every day; (ii) gnignornu modifies the whole predicate vaju a accatto a cicoria in (11b), thus this discourse entails that an event of buying chicoree occurs on every day. From (ii), they conclude that the complex predicate vaju a accatto a cicoria refers to one single event, which they fundamentally see as an event of buying chicoree. Hence, even though the complex predicate in question apparently contains the motion verb vaju, it would not involve reference to a motion event, according to Cardinaletti and Giusti.

It should be noted, though, that discourse (12) is also inconsistent, intuitively for similar reasons as discourse $(11 \mathrm{~b})$ : 


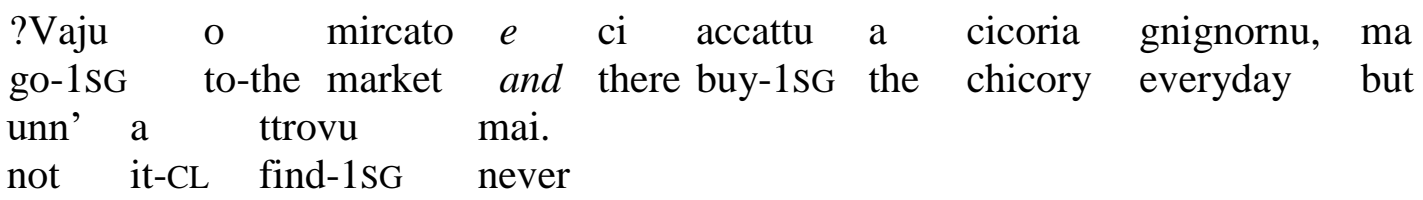

'I go to the market and I buy chicoree there every day, but I never find it.'

Since (12) contains an overt coordination of two clauses (one referring to a motion event and the other one referring to an event of buying chicoree), the fact that (12) is unacceptable shows that the unacceptability of (11b) does not depend on (11b)'s alleged reference to a single event of buying chicoree.

We submit that the contrast in (11a,b) shows that DIC and the infinitival construction differ from one another with respect to their modal properties: on the one hand, the infinitival construction (11a) is intensional with respect to $\mathrm{V}_{2}$, in the sense that it does not entail that a $\mathrm{V}_{2}$ event occurs on every day in the actual world but only that such an event occurs on every day in the possible worlds that are projected by the intentions of the subject; on the other hand, the DIC (11b) is extensional with respect to $\mathrm{V}_{2}$, that is, it does entail that a $\mathrm{V}_{2}$-event occurs on every day in the actual world. This is not meant to deny that DIC has a single event interpretation, in some sense to be made precise, but it suggests that the relevant sense of single event is more complex than it has been thought so far. We'll come back to this issue in section 3.6, while discussing the connection to serial verbs.

\subsection{No grammaticalization of $V_{1}$ as a tense/aspect marker}

When $\mathrm{V}_{1}$ is one of the motion verbs iri 'go' and vèniri 'come', it may appear plausible to regard it as having the status of a tense/aspect marker. Indeed, cross-linguistically the verbs go and come have often been found to be recruited for the encoding of future/past tense notions. For example, in French the verbs aller and venir have both auxiliary uses as future and past tense markers, respectively, as shown in (13a,b):

$$
\begin{aligned}
& \text { a. Je vais manger chez moi. } \\
& \text { I go-1SG eat-INF by me } \\
& \text { 'I'm going to eat at home.' }
\end{aligned}
$$

Notice that in such uses no restrictions are in place regarding the actional type of $\mathrm{V}_{2}$, in particular $\mathrm{V}_{2}$ can be a purely stative verb, as shown in (14a-d): 
a. Je vais être malade.
I go-1SG be-INF sick
'I'm going to be sick.'

b. Je vais le savoir.

I go-1SG it-CL know-INF

'I'm going to know that.'

c. Je viens d' être malade.

I come-1SG from be-INF sick

'I have just been sick.'

d. Je viens de le savoir.

I come-1SG from it-CL know-INF

'I've just learnt that.'

Crucially, however, in DIC a purely stative $\mathrm{V}_{2}$ is unacceptable, as shown in (15a-d) (see Accattoli and Todaro 2017):
a. *Vaju a ssugnu malatu.
go-1SG a be-1SG sick
b. *U vaju a ssacciu.
it-CL go-1SG a know-1SG
c. *Vegnu a ssugnu malatu.
come-1SG a be-1SG sick
d. *U vègnu a ssacciu.
it-CL come-1SG a know-1SG

Notice that motion verbs, in their lexical uses, are not compatible with purely stative complements, as shown by the contrast between the following English examples:

(16) a. Mary went to the casino to win enough money to pay off her debts.

b. John came to my house to pick up a book.

(17) a. *Mary went to the casino to have enough money to pay off her debts.

b. $\quad * J o h n$ came to my house to hold a book with him.

On the one hand, the events denoted by the infinitival complements in $(16 \mathrm{a}, \mathrm{b})$ have a spatial location, and this overlaps with the goal of the motion events denoted by the main clauses, giving 
rise to an interpretation in which the subject moves to a certain location to perform a certain action at that location. On the other hand, the states denoted by the infinitival complements in $(17 \mathrm{a}, \mathrm{b})$ do not have a spatial location in the first place, a fortiori they do not have a spatial location that may overlap with the goal of the motion events; as a result, those sentences lack a coherent interpretation. Therefore, if go and come in DIC retain the thematic requirements they have in their uses as motion verbs, the ungrammaticality of (15a-d) is expected.

Previous work addressing the issue of the (non) grammaticalization of $\mathrm{V}_{1}$ in DIC is Accattoli and Todaro (2017). The authors argue that DIC is not the output of a grammaticalization process. In particular, they reply to an argument by Cardinaletti and Giusti (2001, 2003) which was aimed at showing the loss of lexical content of $\mathrm{V}_{1}$ in DIC. Cardinaletti and Giusti (2001: 377, 2003: 39) use a test involving the adverb agghiri ('toward') to show that the motion verb in DIC no longer projects a goal, unlike what it does in the infinitival construction. They claim that there is a contrast of grammaticality between (18a) and (18b), as indicated below:

$$
\begin{aligned}
& \text { a. } \begin{array}{l}
\text { Gaju a mmanciu agghiri a casa. } \\
\text { Go-1sG a eat-1sG towards to house }
\end{array} \\
& \text { b. Vaju a mmanciari agghiri a casa. } \\
& \text { Go-1sG a eat-INF towards to house } \\
& \text { 'I go home to eat.' }
\end{aligned}
$$

Accattoli and Todaro (2017) observe that not only does agghiri have the directional meaning 'towards', but also the approximative sense 'around', which makes (18a) acceptable as indicated below:

$$
\begin{aligned}
& \text { Vaju a mmanciu agghiri } \mathrm{a}^{5} \text { casa. } \\
& \text { Go-1SG a eat-1SG } \\
& \text { 'I go eat near home.' }
\end{aligned}
$$

The possibility of the approximative interpretation of agghiri is shown in the following real context, involving a stative verb:

$$
\begin{aligned}
& {[\ldots] \text { lui pure c'è stato agghiri ccà (da queste parti, ndt)! }} \\
& \text { 'He has been around here too.' }
\end{aligned}
$$

\footnotetext{
${ }^{5}$ Notice that the element $a$ can also correspond to the definite article ('the').

6 The example comes from a wiretap published in: http://www.antimafiaduemila.com/home/primo-piano/62344operazione-monte-reale-se-il-risolvi-problemi-e-messina-denaro.html. Notice that the Italian translation of agghiri $c c a$, indicated in parenthesis in (19), also makes it clear that this adverbial is interpreted as an approximative (Italian da queste parti means 'around here').
} 
Following Accattoli and Todaro (2017), we propose that a spatial adverb can be accepted in a DIC only if it is semantically and pragmatically compatible with both $\mathrm{V}_{1}$ and $\mathrm{V}_{2}$. Hence, (18a) is acceptable insofar as we interpret agghiri a casa as an (approximative) locative adverb and the latter is compatible both with go (e.g., vaju agghiri a casa 'I'm going near home') and eat (e.g. manciu agghiri a casa 'I'm eating near home'). The same is true of adjuncts, that is, an adjunct is acceptable in a DIC only if it is semantically and pragmatically compatible with both $\mathrm{V}_{1}$ and $\mathrm{V}_{2}$, as shown in (20a-c) (Accattoli and Todaro 2017: 192-193):

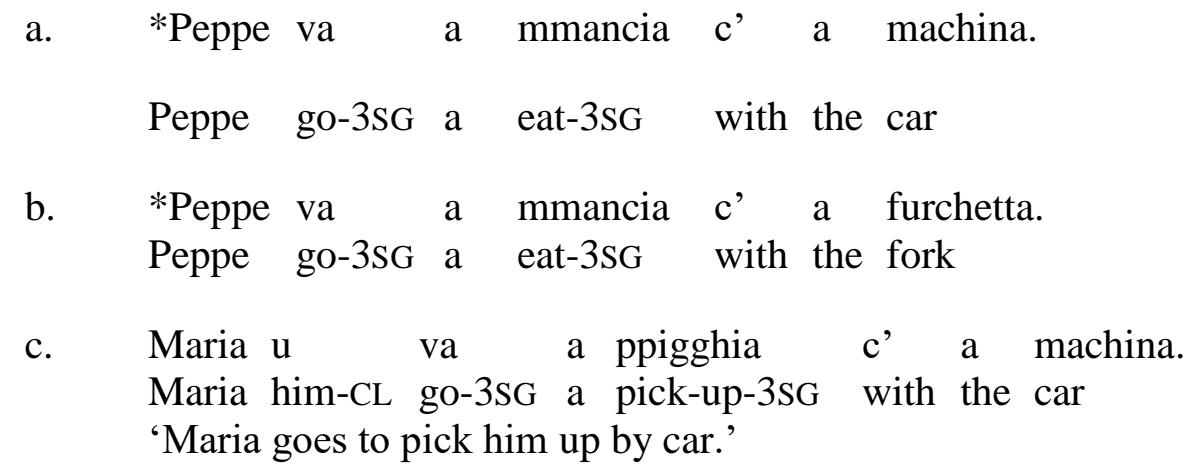

Sentence (20a) is unacceptable because the adjunct c'a machina ('by car') is pragmatically incompatible with the $\mathrm{V}_{2}$ manciari ('eat'), while the unacceptability of (20b) is due to the pragmatic incompatibility of the adjunct c'a furchetta ('with the fork') with the $\mathrm{V}_{1}$ iri ('go'). On the other hand, sentence (20c) is acceptable because the adjunct $c$ 'a machina is semantically and pragmatically compatible with both the $\mathrm{V}_{1}$ iri ('go') and the $\mathrm{V}_{2}$ pigghiari ('pick up').

To summarize, the data considered in this section provide evidence that iri and vèniri, the likeliest verbs to be grammaticalized, have their ordinary lexical semantics in DIC. The same conclusion can be drawn, a fortiori, for the other motion verbs that can appear as $\mathrm{V}_{1}$ in DIC.

\section{Serialization of events}

In this section, we will argue that DIC exemplifies a particular kind of Serial Verb Construction (SVC; Aikhenvald 2006, 2011). By looking at a number of parameters that have been individuated in the literature on SVCs, we will show that DIC corresponds to Aikhenvald's asymmetrical contiguous SVC with concordant marking of inflectional features.

\subsection{Definition and properties of Serial Verb Constructions}

By SVC, one typically intends a sequence of verbs which belong to a single clause, describe a single event, and share one set of morphosyntactic features. Consider the following example from Yoruba (Niger-Congo): 
he take book come

'He brought the book.'

As remarked in Bamgbose (1974: 19), sentence (21) describes an integrated situation in which the 'take' event and the 'come' event must be spatio-temporally contiguous-whence the characteristic "serial verb" reading that the subject comes holding the book. In other words, (21) can be shown to involve a complex event, making up a single event structure. For what concerns the morphosyntactic properties of (21), one can observe that the two verbs $\left(\mathrm{V}_{1}\right.$ and $\left.\mathrm{V}_{2}\right)$ share the $3^{\text {rd }}$ person singular subject and therefore the morphosyntactic feature $3 \mathrm{SG}$, which is not expressed explicitly because Yoruba is an isolating language.

Aikhenvald (2006) classifies SVCs as belonging to one or the other of two broad groups: asymmetrical SVCs and symmetrical SVCs. Asymmetrical SVCs consist of a minor verb from a closed class (possibly a class of motion verbs), and a major verb from an open class, which is seen as the head of the SVC and determines whether the whole construction is transitive or intransitive (Aikhenvald 2006: 22); ${ }^{7}$ as is well-known from the typological literature, minor verbs tend to grammaticalize into markers of direction, aspect, and valency-changing crosslinguistically. Symmetrical SVCs, on the other hand, consist of verb components chosen from major lexical classes. Aikhenvald identifies some properties as criterial for the status of SVCs (no matter whether symmetrical or asymmetrical):

(S1) they are constructions containing no marker of syntactic dependency between the verb components;

(S2) they are distinct from idiomatic double verb sequences which have restrictions on their mood, tense and aspect choices;

(S3) their verb components share arguments;

(S4) their verb components may bear the same inflectional features (concordant marking);

(S5) they describe what is conceptualized as one integrated situation, or one single eventsuch an event may be composed of a series of sub-events.

Several authors have pointed out that there are similarities between DICs and SVCs (Cardinaletti and Giusti 2001, Manzini and Savoia 2005, Cruschina 2013). In the following subsections, we will check for the SVC status of DIC by considering the properties in (S1)-(S5) one after the other.

\subsection{The empty marker}

Although the connecting element $a$ in DIC comes from the Latin coordinating particle $a c$ (Rohlfs $1969),{ }^{8}$ synchronically it does not mark any syntactic dependency, be it a coordination or a

\footnotetext{
${ }^{7}$ The terms minor/major verbs were introduced by Durie (1997).

${ }^{8}$ The alternative hypothesis is that the connecting element $a$ of DIC would derive from the Latin preposition $a d$, as the homophonous element that one finds in the infinitival construction.
} 
subordination (see sect. 2.1.3). Aikhenvald describes such elements as the connecting element of DIC as empty markers, which she characterizes as follows:

"An erstwhile marker of dependency between two verbs may lose its productivity, its meaning and gradually become an empty morpheme. The sequence of verbs containing such a semantically empty marker may have all the features of a serial verb construction. The marker itself no longer indicates a dependency relation - it is a pure and simple indicator of a serial verb." (Aikhenvald 2011: 21)

As pointed out by Cruschina (2013), in some varieties of Sicilian DIC does not even have the connecting element $a$, thus $\mathrm{V}_{1}$ and $\mathrm{V}_{2}$ are contiguous at the surface in these varieties. This is shown in (22) for Pantesco, the variety spoken on the island of Pantelleria:

$$
\begin{aligned}
& \text { Vaju vidu. } \\
& \text { go-1SG see-1SG } \\
& \text { 'I go see (it).' }
\end{aligned}
$$

[Cruschina 2013: 271]

Here the event verb occurs immediately after the motion verb and the interpretation of the sentence is the same as would be obtained for the full-fledged DIC Vaju a vidu.

\subsection{No idiomaticity}

Although they are known to display a defective paradigm in some varieties (Cardinaletti and Giusti 2001, Cruschina 2013, Manzini and Savoia 2005, Di Caro 2015, Di Caro and Giusti 2015, Di Caro 2017, this volume), it is clear that DICs differ from idiomatic constructions, whose meaning is completely frozen and non-compositional, and they are the result of productive morphosyntactic processes: indeed, they are attested in the indicative and imperative mood, in both the present and (imperfective and perfective) past tense in at least some varieties of Sicilian (see type 2 discussed in section 2.1.1). ${ }^{9}$

\subsection{Argument sharing}

Turning to the argument sharing property in (S3), we observe that the verb components $\mathrm{V}_{1}$ and $\mathrm{V}_{2}$ in DICs systematically share arguments. Usually, the shared argument is the subject. To be precise, subject sharing occurs in DICs featuring as $\mathrm{V}_{1}$ any one of the motion verbs go, come, and pass by. However, most interesting for us are DICs with the causative motion verb mannari, which display a different pattern of argument sharing, as we will see in section 4.1.

\footnotetext{
9 While discussing the issue here would take us too far afield, we note that the problem of defectivity is orthogonal to the serial verb status of DIC. We refer the reader to Cruschina (2013) for an in-depth analysis of the relevant data based on Maiden's (2004) concept of $N$-pattern configuration.
} 


\subsection{Feature Matching}

Finally, let's turn to the (optional) property of SVCs by which their verb components bear the same inflectional features (Feature Matching). Although not all SVCs have this property, Feature Matching characterizes an important subclass of SVCs-in Aikhenwald's terminology, those SVCs that show "concordant marking of inflectional features". DIC pattern like SVCs belonging to this subclass: as we saw in section 2.1.1, $\mathrm{V}_{1}$ and $\mathrm{V}_{2}$ are inflected for the same person and tense/aspect features in DIC.

\subsection{Single event}

DIC has been claimed to describe a single event, fundamentally of the same type as a $\mathrm{V}_{2}$-event. However, the test used to prove this "single event" property, as we saw in section 2.2, actually shows that DIC is extensional with respect to $\mathrm{V}_{2}$ and the infinitival construction intensional with respect to the same position. As far as the test examined in section 2.2 goes, DIC might still involve a complex event $e_{3}$ encompassing a separate motion event component $e_{1}$. We do believe that the interpretation of DIC involves such a motion component (there is evidence for this, which we discuss in 2.3) but we also believe that the intuitive characterization of DIC as involving a single event interpretation is correct, in some sense. The difficulty with assessing the single event property is due to the fact that the notion of a 'single event' (or 'one integrated situation') is hard to define and capture formally. There have been attempts to formalize this notion in terms of the macro-event property (Talmy 2000, Bohnemeyer et al. 2007, Bohnemeyer et al. 2011). Bohnemeyer et al. (2011: 48) define the Macro-Event Property (MEP) as follows:

An event-denoting construction has the MEP iff it combines only with those timepositional or durational operators [tenses, time adverbials, temporal clauses] that have scope over all subevents it entails.

We suggest that a fruitful way to prove that DIC has a single event property might consist in showing that DIC has the MEP. Starting from tense, that DIC has the MEP is immediately clear from the property of Feature Matching discussed in section 2.1.1 above. In particular, we saw that the verb components in DIC necessarily bear the same tense/aspect features and are interpreted in the scope of the same tense/aspect operator. Moving to temporal adverbials/clauses, one can show that DIC has the MEP also relative to this kind of temporal operators. Consider $(23 a, b)$ :

(23) a. ?Vaju a ppigghiu u picciriddro rumani ma mi lu runano vènnare. go-1SG a take-1SG the kid tomorrow but to-me him give-3PL Friday 'I go pick up the kid tomorrow but they'll give him to me on Friday.' 
b. Vaju a ppigghiari u picciriddro rumani ma mi lu runano vènnare. go-1SG to take-INF the kid tomorrow but to-me him give-3PL Friday

'I go to pick up the kid tomorrow but they'll give him to me on Friday.'

On the one hand, the temporal adverb rumani 'tomorrow' in (23a) refers to the whole predicate vaju a ppigghiu '(I) go pick up', as a consequence, the event of picking up the kid has to occur on the day denoted by rumani and continuing by saying that the kid will be picked up on Friday instead gives rise to oddness. On the other hand, rumani in (23b) can selectively scope over vaju '(I) go', to the exclusion of pigghiari u picciriddro 'to pick up the kid', as a consequence only the event of going has to occur on the day denoted by rumani and the continuation is fine.

Summing up, in sect. 3 we have considered five properties taken by Aikhenvald as criterial for the status of SVC and we have shown that DIC has all of them. The general conclusion, assuming Aikhenvald's typology of SVCs, is that DIC can be naturally regarded as a contiguous asymmetrical SVC with Feature Matching.

\section{The analysis}

\subsection{DIC with the causative motion verb mannari}

Previous formal analyses of DIC (e.g. Cardinaletti and Giusti 2001) assume that the motion verb $\mathrm{V}_{1}$ in DIC is auxiliary-like. According to such analyses: (i) $\mathrm{V}_{1}$ is not a verb with full lexical content, truly denoting a property of events of motion, but a "semi-lexical" verb merged in the extended projection of $\mathrm{V}_{2}$; (ii) only $\mathrm{V}_{2}$ has full lexical content and interpreted inflectional features, while $\mathrm{V}_{1}$ inherits its features from $\mathrm{V}_{2}$. Problematic for this analysis are DICs with the causative motion verb mannari 'send'. Consider (24):

$$
\begin{array}{lllll}
\text { Ti mannu a ddicu ddra cosa. } & \text { a } \\
\text { To-you send-1SG a say-1SG that thing } & \text { a } \\
\text { 'I'm sending someone to say that thing to you.' }
\end{array}
$$

By Feature Matching, the person feature on mannu is the same as the one on ddicu, that is, first singular. However, this feature appears to be interpreted only on mannu: indeed, the agent of ddicu is not the speaker but some other person $x$ such that the speaker sends $x$ so that $x$ says the relevant thing to the hearer. This is most clear in (25):

$$
\begin{array}{lllllllll}
\text { Un } & \text { ti } & \text { lu } & \text { mannu } & \text { a } & \text { ddicu, ti } & \text { lu } & \text { ricu } & \text { iu. } \\
\text { NEG to-you } & \text { it-CL } & \text { send-1SG } & \text { ac } & \text { say-1SG to-you } & \text { it-CL } & \text { say-1SG } & \text { me } \\
\text { 'I do not send anyone to say it to you, I say it to you myself.' } &
\end{array}
$$

If the agent of ddicu were the speaker, (25) would be contradictory, as it would imply both that I do not say it to you and that I say it to you. But (25) is a perfectly consistent discourse. 


\subsection{Formal analysis}

In this section we present our analysis of DIC, both at the level of morphosyntactic configuration (section 4.2.1) and at the formal semantic level (section 4.2.2); then we show how our analysis accounts for the main properties of DIC, including the morphosyntax-semantics mismatch described in section 4.1 (section 4.2.3).

\subsubsection{Morphosyntax}

We propose that $\mathrm{V}_{1}$ and $\mathrm{V}_{2}$ are lexical verbs which combine according to an operation of "lexical concatenation" to form a complex verb predicate $\left[\mathrm{v} \mathrm{V}_{1} \mathrm{ac} \mathrm{V}_{2}\right]^{10}$ with specific argument structure and semantic properties, the latter of which will be discussed in section 4.2.2. Concerning the argument structure of [ $\mathrm{v} \mathrm{V}_{1}$ ac $\mathrm{V}_{2}$ ], this is so determined that its external argument (subject) is the same as the external argument of $\mathrm{V}_{1}$, while its internal arguments are the same as the internal arguments of $\mathrm{V}_{2}$. Crucially, although it is formed from two verbs, the complex predicate [ $\mathrm{v}_{1}$ ac $\mathrm{V}_{2}$ ] counts as just one single predicate from the morphosyntactic point of view. This aspect of the analysis has important consequences regarding how inflectional features are realized in DIC (for reasons of space we will uniquely focus on person features in what follows, though our claims may be extended to TAM features): (a) on the one hand, the person features occur only once at Logical Form, in a position in which they apply to the whole predicate $\left[v \mathrm{~V}_{1}\right.$ ac $\left.\mathrm{V}_{2}\right]$, being thus interpreted relative to the external argument of the latter-intuitively, this external argument is what appears as the subject of $\mathrm{V}_{1}$, e.g. the implicit 1SG person subject in (25) - ; on the other hand, those same features have to be morphophonologically realized twice in [v $V_{1}$ ac $V_{2}$, i.e., once on the $\mathrm{V}_{1}$ component and once on the $\mathrm{V}_{2}$ component, although they are not interpreted relative to the external argument of $\mathrm{V}_{2}$. As we'll see shortly, this consequence of the morphosyntactic analysis, taken along with the semantic ingredients given in section 4.2.2 below, makes it possible to predict that the agent of ddicu in (25) is not the speaker uttering (25), being rather identified with the theme of mannu according to the composition rule in (33) below.

Before presenting our semantic analysis, we make a short excursion to examine an alternative account that might be proposed for the particular way in which inflectional features are realized in DIC, namely one based on Kratzer's (2009) mechanism of Feature Transmission Under Binding. The conclusion will be that the alternative account does not constitute a viable solution to our problem. As some colleagues have suggested to us, the morphosyntax-semantics mismatch brought out by the $1 \mathrm{SG}$ person feature showing up on $\mathrm{V}_{2}$ in (25) is reminiscent of the morphosyntax-semantics mismatch that has been observed in sentences like (26) and (27) (both from Kratzer 2009), taken in the bound readings specified below:

(26) I'm the only one around here who can take care of my children.

Bound reading: I am the only person $x$ such that $x$ can take care of $x$ 's children

\footnotetext{
${ }^{10}$ From now on, we will use the sign $a c$ as standing for the element (sometimes non-overt) which concatenates $\mathrm{V}_{1}$ and $\mathrm{V}_{2}$ in DIC. This choice reflects the historical derivation of the connecting element of DIC from the Latin particle ac (Rohlfs 1969).
} 
Only you eat what you cook.

Bound reading: You are the only person $x$ such that $x$ eats what $x$ cooks

On the bound readings of these sentences, ${ }^{11}$ the boldfaced $1 \mathrm{st} / 2 \mathrm{nd}$ person pronouns in them appear to be interpreted as plain variables bound by quantifiers, not as the indexical pronouns referring to the speaker/hearer of the context, which they prima facie seem to be (Partee 1989, Schlenker 1999, Heim 2008, Kratzer 2009). Kratzer's idea, closely elaborating on Heim (2008), is that the boldfaced pronouns in these examples are "minimal pronouns", i.e., pronouns which are born without certain features superficially appearing on them (in this case, without the 1st/2nd person feature) and are thus interpreted by the semantic component without those features. For instance, the minimal pronoun you in (27) is interpreted as the plain variable $x$ in the logical structure $\left(27^{\prime}\right)$ :

\section{$\left[[\text { Only you }]_{x} \lambda x[x\right.$ eat what $x$ cook $\left.]\right]$}

How does a minimal pronoun such as you in (27) come to acquire the 2nd person feature that it shows at the surface? Kratzer proposes that this comes about via a morphophonological mechanism that she calls Feature Transmission Under Binding: simplifying a little bit, under the bound reading of (27), you (corresponding to the rightmost occurrence of $x_{[n]}$ in the Logical Form (27") below) receives its $2^{\text {nd }}$ person feature from the closest element that binds it in the structure; this closest binding element in (27") is the v head, which in turn has to agree via Specifier-Head Agreement with the pronoun $x_{[n]}$ in its specifier position, which receives the 2 nd person feature via Feature Transmission from its binder $\lambda[n][2]$, which in turn originates from raising of the inherently 2nd person DP [Only you $]_{[n][2]}$. Hence, ultimately, the source of the (uninterpreted) 2nd person feature of you in (27) — under the bound reading of this sentence - is the occurrence of the genuinely 2nd person pronoun you in the subject DP only you (in this DP only is the 2nd person feature truly interpreted).
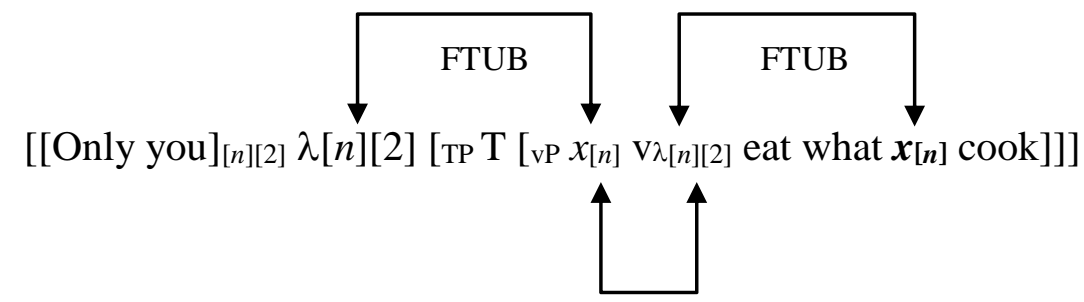

Spec-Head

Agreement

\footnotetext{
${ }^{11}$ A non-bound reading should also be possible for (26) and (27). On their non-bound reading, (26) entails that no one other than me can take care of my children and (27) entails that no one other than you eats what you cook.
} 
Turning to our problematic sentence in (24), repeated here as (28), we assume that its underlying structure is as in $\left(28^{\prime}\right)$ :

(28) Ti mannu a ddicu ddra cosa.

'I'm sending someone to say that thing to you.'

$$
\left[[\operatorname{pro}]_{[n][1]} \lambda[n][1]\left[\mathrm{TP} \mathrm{T}\left[\mathrm{vP}\left[{ }^{\text {agent }} x_{[n]}\right] \mathrm{v} \lambda[n][1][\text { send ac say }]\left[{ }^{\text {theme }} \text { that thing }\right]\left[{ }^{\text {beneficiary }} \text { to you }\right]\right]\right]\right]
$$

In spite of the similarity between the problems they raise - both (28) and (26)-(27) have a certain feature superficially showing up which is not interpreted by the semantic component - it should be clear that Kratzer's mechanism of Feature Transmission, which was originally intended to deal with (26)-(27), does not apply in the case of (28): the syntactic configuration of the DIC, given in $(28 ')$, does not allow for transmission of the $1^{\text {st }}$ person feature to the two verb components send and say of the concatenated predicate.

\subsubsection{Semantics}

We cast the semantic analysis of DIC in an event semantics framework (Parsons 1990), in which verb predicates denote properties of events, as shown in $(29 a, b)$ below for the verbs iri and manciari, and event participants are introduced through thematic $(\theta)$ role functions, illustrated in (30) for the $\theta$-role agent. ${ }^{12} \mathrm{We}$ assume a type-theoretic framework with $\mathbf{E}$ as the semantic type of events; other semantic types are as in Montagovian semantics (e.g. e is the type of individuals and $\mathbf{t}$ the type of truth values).

$$
\begin{array}{ll}
\text { a. } & {[[[\mathrm{vP} \text { iri }]]]=\lambda e_{\mathrm{E}} \cdot \mathrm{GO}(e)} \\
\text { b. } & {[[[\mathrm{vP} \text { mangiari }]]]=\lambda e_{\mathrm{E}} \cdot \operatorname{EAT}(e)}
\end{array}
$$

We assume an indexical analysis of person features, according to which these features denote functions that take theta roles $\theta$ as arguments and impose on $\theta$ the condition that the selected participant be suitably related to (in the simplest case, be identical with) the speaker/hearer of the context. This is illustrated in (31) for the $1 \mathrm{SG}$ person $^{13}(c, w$ are the context and world parameter, respectively, of the denotation function [[ ... ]], $c_{\mathrm{a}}$ is the speaker of context $c$, " $x=c_{\mathrm{a}}$ " is the definedness condition requiring identity to the speaker):

$$
[[1 \mathrm{SG}]]_{c, w}=\lambda \theta_{\langle<\mathrm{e},\langle\mathrm{E}, \mathrm{t}\rangle>,\langle\mathrm{E}, \mathrm{t}\rangle>} \cdot \lambda x_{\mathrm{e}}: x=c_{\mathrm{a}} \cdot \lambda f_{\langle\mathrm{E}, \mathrm{t}\rangle} . \lambda e_{\mathrm{E}} \cdot f(e) \& \theta(e)=x
$$

The semantics of the concatenated predicate $\left[\mathrm{v} \mathrm{V}_{1}\right.$ ac $\left.\mathrm{V}_{2}\right]$ is based on an operation of event concatenation, defined in (32):

\footnotetext{
${ }^{12}$ Structurally similar interpretations are provided for the $\theta$-roles theme, goal, location, etc.

${ }^{13}$ For simplicity, we do not give a separate analysis of person and number features here.
} 
(32) Let $e_{1}$ and $e_{2}$ be spatio-temporally contiguous events. The event concatenation $\left(e_{1} \bullet e_{2}\right)$ is an event whose temporal trace $\tau\left(e_{1} \bullet e_{2}\right)$ is the convex interval obtained by summing the temporal traces of $e_{1}$ and $e_{2}$.

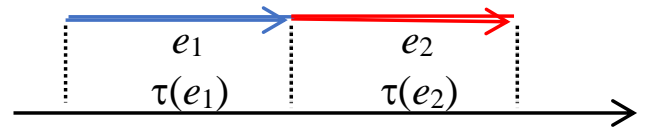

Fig. 1. Event concatenation

Notice that the concatenated event $\left(e_{1} \bullet e_{2}\right)$ is a single (although complex) event, not a set of two single events. As such, it can be argument of a higher concatenation, e.g. $\left(\left(e_{1} \bullet e_{2}\right) \bullet e_{3}\right)$ (this is arguably what happens in the event composition of sequences like Go, buy and come home).

The semantic value of [ $\mathrm{VP}_{\mathrm{P}} \mathrm{V}_{1}$ ac $\mathrm{V}_{2}$ ] is computed according to the composition rule in (33) (we present this rule as the semantic value of the connecting element $a c ; f_{1}$ and $f_{2}$ are the properties of events corresponding to the verb predicates $V_{1}$ and $V_{2}$, respectively):

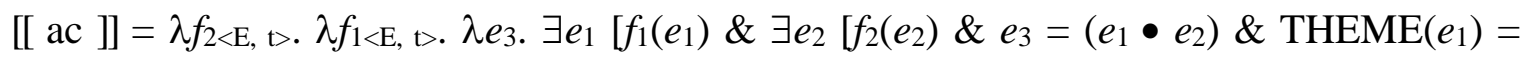
$\left.\left.\operatorname{AGENT}\left(e_{2}\right) \& \operatorname{GOAL}\left(e_{1}\right)=\operatorname{LOCATION}\left(e_{2}\right)\right]\right]$

This complex function provides for argument sharing between $\mathrm{V}_{1}$ and $\mathrm{V}_{2}$ : in particular, the theme of $\mathrm{V}_{1}$ (i.e., the participant in the motion event which undergoes the change of location) is identified with the agent of $\mathrm{V}_{2}$, which predicts that for $\mathrm{V}_{1}=$ iri/vèniri/passari the shared argument is the subject of both $V_{1}$ and $V_{2}$ (see the interpretation of (1), repeated here as (34)), while for $V_{1}$ $=$ mannari the shared argument is the object of $\mathrm{V}_{1}$ and the subject of $\mathrm{V}_{2}$ (see the interpretation of (28)).

Finally, as standard in neo-Davidsonian event semantics, we assume that a default sentence-level closure operation determines existential binding of the event variable.

\subsubsection{Application of the analysis to some examples}

Let's start from the simple example (34). In (34') we give the Logical Form of (34), which makes it clear that the person features occur only once at the level of semantic interpretation. Logical Form (34') is evaluated as in (34") (for limits of space, we skip the steps of the full semantic derivation):

(34) Vaju a mmanciu a casa.

'I go eat at home.'

$$
[\exists \text {-closure }[1 \mathrm{SG}[[\text { agent(pro)] [go ac eat] [location(home)]]]] }
$$



$\operatorname{AGENT}\left(e_{2}\right) \& \operatorname{GOAL}\left(e_{1}\right)=\operatorname{LOCATION}\left(e_{2}\right) \& \operatorname{LOCATION}\left(e_{3}\right)=$ the-house-of- $\left.\mathrm{c}_{\mathrm{a}} \& \operatorname{AGENT}\left(e_{3}\right)=\mathrm{c}_{\mathrm{a}}\right]$

According to (34"), sentence (34) is true (in a context c) at the complex factual condition that: (a) there is an event $e_{3}$ which is the concatenation of an event $e_{1}$ of going and an event $e_{2}$ of eating, (b) the participant in $e_{1}$ which undergoes change of location is the same as the eater in $e_{2}$, (c) the location in space to whom $e_{1}$ is directed is the same as the location in which $e_{2}$ takes place, namely the house of the speaker who utters (34) (in context c), and (d) the agent of the concatenated event $e_{3}$ is the speaker who utters (34) (in context c).

We now turn to (28), repeated here as (35). In (35') we give the logical form of (35), which is then evaluated as in (35") ( $c_{\mathrm{a}}$, as before, is the speaker of context $\mathrm{c}$, while $\mathrm{c}_{\mathrm{h}}$ is the hearer of c):

(35) Ti mannu a ddicu ddra cosa.

'I'm sending someone to say that thing to you.'

[ $\exists$-closure [1SG [[agent(pro)] [send ac say] [theme(that-thing)][beneficiary(you)]]]]

$$
\begin{aligned}
& {\left[\left[\left(35^{\prime}\right)\right]\right] \mathrm{c,w}=1 \text { iff } } \exists e_{3} \exists e_{1} \exists e_{2}\left[\operatorname{SEND}\left(e_{1}\right) \& \operatorname{SAY}\left(e_{2}\right) \& e_{3}=\left(e_{1} \bullet e_{2}\right) \& \operatorname{THEME}\left(e_{1}\right)=\right. \\
& \operatorname{AGENT}\left(e_{2}\right) \& \operatorname{GOAL}\left(e_{1}\right)=\operatorname{LOCATION}\left(e_{2}\right) \& \operatorname{THEME}\left(e_{3}\right)=\text { that } \\
&\text { thing } \left.\& \operatorname{BENEFICIARY}\left(e_{3}\right)=\mathrm{c}_{\mathrm{h}} \& \operatorname{AGENT}\left(e_{3}\right)=\mathrm{c}_{\mathrm{a}}\right]
\end{aligned}
$$

According to (35"), sentence (35) is true (in a context c) at the complex factual condition that: (a) there is an event $e_{3}$ which is the concatenation of an event $e_{1}$ of sending and an event $e_{2}$ of saying, (b) the participant in $e_{1}$ which undergoes change of location is the same as the person who says something in $e_{2}$, (c) the location to whom $e_{1}$ is directed is the same as the location in which $e_{2}$ takes place, (d) the content that is said in $e_{3}$ is the thing referred to by uttering "that thing" (in context c), (e) the person who receives the content said in $e_{3}$ is the hearer (of context c), and (f) the agent of the concatenated event $e_{3}$ is the speaker who utters (35) (in context c).

Finally, we analyze example (20c), repeated here as (36), which involves an adjunct expressing an instrumental role. In (36') we give the logical form of (36), which is then evaluated as in (36"):

(36) Maria u va a ppigghia c'a machina.

'Maria goes to pick him up by car.'

(36') $[\exists$-closure [3SG [[agent(Maria)] [go ac pick-up] [theme(him)][instrument(the-car)]]]]

(36") $\left[\left[\left(36^{\prime}\right)\right]\right] \mathrm{c}_{\mathrm{c}, \mathrm{w}}=1 \quad$ iff $\exists e_{3} \exists e_{1} \exists e_{2}\left[\mathrm{GO}\left(e_{1}\right) \& \operatorname{PICK}-\operatorname{UP}\left(e_{2}\right) \& e_{3}=\left(e_{1} \bullet e_{2}\right) \& \operatorname{THEME}\left(e_{1}\right)\right.$ $=\operatorname{AGENT}\left(e_{2}\right) \& \operatorname{GOAL}\left(e_{1}\right)=\operatorname{LOCATION}\left(e_{2}\right) \& \operatorname{THEME}\left(e_{3}\right)=$ $\operatorname{him} \& \operatorname{INSTRUMENT}\left(e_{3}\right)=$ the-car $\& \operatorname{AGENT}\left(e_{3}\right)=$ Maria] 
According to (36"), sentence (36) is true (in a context c) at the complex factual condition that: (a) there is an event $e_{3}$ which is the concatenation of an event $e_{1}$ of going and an event $e_{2}$ of picking up, (b) the participant in $e_{1}$ which undergoes change of location is the same as the person who picks up someone in $e_{2}$, (c) the location to whom $e_{1}$ is directed is the same as the location in which $e_{2}$ takes place, (d) the person who is picked up in $e_{3}$ is the one that the clitic $u$ ('him') refers to (in context c), (e) the instrument used in $e_{3}$ is the relevant car (in context c), and (f) the agent of the concatenated event $e_{3}$ is the agent of both $e_{1}$ and $e_{2}$, i.e. Maria. Notice that the entity playing the instrumental role in the concatenated event $e_{3}$ also refers to its sub-components $e_{1}$ and $e_{2}$, that is, this entity is understood as playing the instrumental role in each of $e_{1}$ and $e_{2}$ as well and it has thus to be compatible with both $e_{1}$ and $e_{2}$ (recall the unacceptability of $(20 \mathrm{a}, \mathrm{b})$, in which the instrumental adjunct has been found to be compatible with only one of the two event components).

\section{Conclusion}

Our analysis contributes to the formal study of complex event predicates both at the level of morphosyntax and semantics and sheds light on new data. We have argued that a proper formal treatment of DIC calls for an operation of Lexical Concatenation building complex event predicates out of a motion event predicate $V_{1}$ and an event predicate $V_{2}$, whose semantic counterpart is an operation of event concatenation which builds complex events sharing thematic participants. The data with mannari that we have considered are problematic for previous analyses based on syntax, in particular Cardinaletti and Giusti's (2001) analysis holding that $V_{1}$ is auxiliary-like and inherits its features from the lexical head $\mathrm{V}_{2}$ of DIC. The analysis we have proposed uniformly accounts for DICs with any of the admissible motion verbs in $\mathrm{V}_{1}$. The morphosyntax/semantics mismatch brought out by the data with mannari is naturally explained on the assumption that the inflectional (person) features apply to the complex (serial) verb [ $\mathrm{V}_{1}$ ac $\mathrm{V}_{2}$ ] yielded by Lexical Concatenation and are thus interpreted only once with respect to the external argument of this complex verb. At the same time, at the level of morphophonological structure, the features are realized twice, once on each verb component. In passing we have also explained why a mechanism such as Kratzer's Feature Transmission under Binding could not be invoked to explain the morphosyntax/semantics mismatch in DIC.

A further aspect of DIC that we have discussed is the similarity with serial verb constructions (SVCs) attested in typologically different languages and analyzed in literature. We have argued that DIC is an instance of what Aikhenvald (2006) calls asymmetric SVC. To our knowledge, the analysis proposed here is the first attempt to provide an explicit account of such SVCs encompassing both a formal semantic and a morphosyntactic component. Our analysis opens the question of what the relation is between event concatenation and other kinds of complex event-building operations that one may need to assume to formally account for other types of SVCs.

Finally, a problem to be addressed in future research concerns the productivity of DIC: why is the general operation of event concatenation apparently restricted to those combinations 
[motion verb + event verb] that involve the four motion verbs mentioned at the outset? What is the reason for the reported restriction to the motion verbs in question? Although variation is reported between more restrictive and more liberal varieties of Sicilian regarding what motion verbs are allowed in DIC, it seems that speakers of no variety recognize sentences such as (37) as possible DICs (Di Caro 2015):

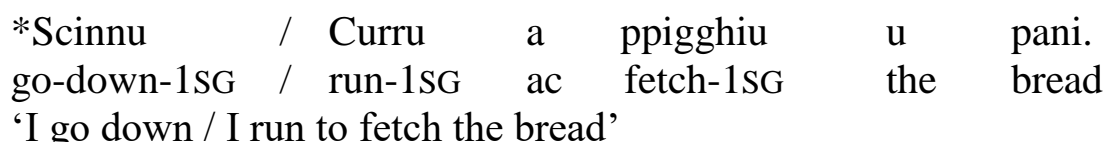

Still, we clearly see the intelligible sense that such sentences would convey, were they used in a suitable context (notice that their infinitival counterparts Scinnu /Curru a ppigghiari u pani are unproblematic). We leave this as an open issue.

\section{References}

Accattoli, Matilde \& Giuseppina Todaro. 2017. Verbes de mouvement et grammaticalisation: le cas du sicilien vaffazzu. In Normes et grammaticalisation : le cas des langues romanes, Malinka Velinova (ed.), 187-210. Sofia: CU "Romanistika".

Aikhenvald, Alexandra Y. 2006. Serial Verb Constructions in a Typological Perspective. In Serial verb constructions: a cross-linguistic typology, Alexandra Y. Aikhenvald \& Robert M. W. Dixon (eds), 1-87. Oxford: Oxford University Press.

Bohnemeyer, Jürgen, Enfield, Nick, Essegbey, James, Ibarretxe, Iraide, Kita, Sotaro, Lüpke, Friederike \& Felix K. Ameka. 2007. Principles of event encoding: The case of motion events. Language 83 (3): 495-532.

Bohnemeyer, Jürgen, Enfield, Nick, Essegbey, James \& Sotaro Kita. 2011. The Macro-Event property: The segmentation of causal chains. In Event representation in language and cognition, Jürgen Bohnemeyer \& Eric Pederson (eds), 43-67. New York: Cambridge University Press.

Cardinaletti, Anna \& Giuliana Giusti. 2001. 'Semi-lexical' motion verbs in Romance and Germanic". In Semi-lexical Categories: the function of content words and the content of function words Norbert Corver \& Henk C. van Riemsdijk (eds), 371-414. Berlin: Mouton de Gruyter.

Cardinaletti, Anna \& Giuliana Giusti. 2003. Motion verbs as functional heads. In The Syntax of Italian Dialects, Christina Tortora (ed.), 31-49. New York: Oxford University Press.

Cruschina, Silvio. 2013. Beyond the stem and inflectional morphology: An irregular pattern at the level of periphrasis. In The Boundaries of Pure Morphology: Diachronic and Synchronic Perspectives, Silvio Cruschina, Martin Maiden \& John C. Smith (eds), 262-283. Oxford: Oxford University Press.

Di Caro, Vincenzo N. 2015. Syntactic constructions with motion verbs in some Sicilian dialects: a comparative analysis. MA thesis, Università Ca' Foscari di Venezia. 
Di Caro, Vincenzo N. 2017. The Inflected Construction in the dialects of Sicily: parameters of micro-variation (this volume).

Di Caro, Vincenzo N. \& Giuliana Giusti. 2015. A protocol for the Inflected Construction in Sicilian dialects. In Annali di Ca' Foscari, serie occidentale, vol. 49, 393-422, 1997.

Durie, Mark. 1997. Grammatical structures in verb serialization. In Complex Predicates, Alex Alsina, Joan Bresnan \& Peter Sells (eds), 289-354. Stanford: CSLI.

Heim, Irene. 2008. Features on Bound Pronouns. In Phi Theory: Phi Features across Interfaces and Modules, David Adger, Susana Bejar \& Daniel Harbour (eds), 35-56. Oxford: Oxford University Press.

Kratzer, Angelika. 2009. Making a pronoun: fake indexicals as windows into the properties of pronouns, Linguistic Inquiry, 40 (2): 187-237.

Lehmann, Christian. 2002. Thoughts on Grammaticalization, (2 ${ }^{\text {nd }}$ ed.), Erfurt: Seminar für Sprachwissenschaft der Universität.

Maienborn, Claudia. 2008. On Davidsonian and Kimian States. In Existence: Semantics and Syntax, Ileana Comorovski \& Klaus von Heusinger (eds), 107-130. Dordrecht: Kluwer Academic Publishers.

Manzini, Maria R. \& Leonardo M. Savoia. 2005. I dialetti italiani e romanci. Morfosintassi generativa. Alessandria: Edizioni dell'Orso.

Parsons, Terence. 1990. Events in the Semantics of English: A Study in Subatomic Semantics, Cambridge, MA: MIT Press.

Partee, Barbara. 1989. Binding implicit variables in quantified contexts. In Papers from the 25th Regional Meeting of the Chicago Linguistic Society, Caroline Wiltshire, Randolph Graczyk \& Bradley Music (eds), 342-65. Chicago: Chicago Linguistic Society.

Rohlfs, Gerhard. 1969. Grammatica storica della lingua italiana e dei suoi dialetti, vol. 3: Sintassi e formazione delle parole. Torino: Einaudi.

Ross, John R. 1967. Constraints on variables in syntax. PhD dissertation, MIT.

Schlenker, Philippe. 1999. Propositional Attitudes and Indexicality: A Cross-Categorial Approach. PhD dissertation, MIT.

Talmy, Leonard. 2000. Toward a Cognitive Semantics. Cambridge, MA: MIT Press.

Wiklund, Anna-Lena. 1996. Pseudocoordination is subordination. In Working Papers in Scandinavian Syntax 58: 29-54.

Wiklund, Anna-Lena. 2007. The Syntax of Tenselessness. Tense/Mood/Aspect-agreeing Infinitivals. Berlin: De Gruyter. 